\title{
Vanilla essence non-nutritive sucking, an effective alternative for pain relief during heel-stick procedure in healthy term neonates: A randomized clinical trial
}

\author{
Juan F. Molina-De La Garza, Erika Del C. Ochoa-Correa*, Elsa G. Saucedo-Rodríguez, \\ Isaías Rodríguez-Balderrama, Bárbara G. Cárdenas-Del Castillo, María C. Martínez-Cobos, and \\ Manuel E. De La O-Cavazos
}

Department of Pediatrics, School of Medicine, "Dr. José Eleuterio González" University Hospital, Universidad Autónoma de Nuevo León, Monterrey, Nuevo Leon, Mexico

\begin{abstract}
Objective: The aim of this study is to compare the efficacy of breastfeeding (BF) with non-nutritive sucking (NNS) using a vanilla-scented pacifier as an intervention to relieve pain in healthy term neonates during the heel-stick procedure. Materials and methods: This was a randomized clinical trial of healthy term infants randomly assigned to one of two groups. In both groups, the assigned non-pharmacological method was provided 1 min before the heel stick and up to 5 min after the procedure, which was recorded on video, as well as measures of vital signs of the newborn necessary for the use of the Premature Infant Pain Profile (PIPP) scale. A neonatologist was responsible for giving a score to each newborn in the PIPP scale to measure pain after the procedure. The primary outcome is to compare the PIPP scores in the two groups. Results: A sample of 40 infants were analyzed, of which 21 (52.5\%) were given NNS and $19(47.5 \%)$ BF. It was found that PIPP scores do not differ between the intervention group and the control group: (median [interquartile range]) 12 (7.50-13.50) and 11 (1113), respectively, $(p=0.61)$. Conclusions: $B F$ and NNS are equally effective in controlling pain in term infants during heel stick procedure. While we recommend BF due to its well-known benefits, NNS could be used when BF is not available.
\end{abstract}

Key words: Breastfeeding. Newborn. Pacifiers. Pain. Vanilla.

\section{Introduction}

The definition of pain, according to the International Association for the Study of Pain, is "An unpleasant sensory and emotional experience associated with, or resembling that associated with, actual or potential tissue damage"1. All newborns, even those who do not have complications during birth or who are completely healthy will experience pain, either upon vitamin $\mathrm{K}$ administration, venipuncture for laboratory studies or at the time of specialized studies such as metabolic screening ${ }^{2}$. Assessment of pain in neonates is difficult because they cannot communicate verbally; therefore, it is necessary to use different pain scales using subjective observations and objective measurements such as vital signs ${ }^{3}$.

Scientific evidence shows that controlling pain in newborns has a beneficial effect and improves

\section{Correspondence:}

*Erika del C. Ochoa-Correa

E-mail: erika8ac@hotmail.com
Date of reception: 20-01-2021

Date of acceptance: 12-02-2021 DOI: 10.24875/RMU.21000006
Available online: 18-03-2021 Medicina Universitaria. 2021;23(1):4-10 www.medicinauniversitaria.org

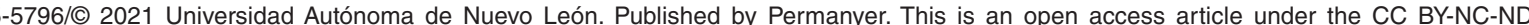
license (http://creativecommons.org/licenses/by-nc-nd/4.0/). 
physiological, hormonal, and behavioral outcomes ${ }^{4}$. There are different methods to relieve pain in newborns depending on the degree of pain, including pharmacological ones, in which opioids such as morphine, fentanyl, remifentanil, and non-opioid analgesics such as acetaminophen are used ${ }^{5}$. At present, different non-pharmacological methods have been used to treat pain when performing procedures in newborns, including breastfeeding (BF), use of sugars such as oral sucrose, non-nutritive sucking (NNS), swaddling the newborn in blankets, music therapy, and skin-to-skin contact $^{6-10}$. The American Academy of Pediatrics recommends in its clinical practice guidelines that various non-pharmacological methods could be used to treat pain when doing minor procedures ${ }^{11,12}$. Most studies on neonatal pain have focused on premature infants, using mainly non-pharmacological methods; however, there are no studies that compare the effectiveness of NNS and $\mathrm{BF}$ in term newborns ${ }^{13}$. The aim of the study was to assess the efficiency of BF and NNS through a vanilla pacifier as options to treat pain in term neonates during heel sticks.

\section{Materials and Methods}

We conducted a randomized open-label controlled trial at a newborn nursery in a tertiary care hospital where term newborns were recruited. This study was approved by our institutional Ethics in Research Committee with registration number PE15-035 and parents of eligible neonates were asked to sign written informed consent before enrolling patients. If they chose not to participate in the study, their neonate would receive BF as pain management when obtaining blood for their metabolic screen.

\section{Participants}

The trial was performed from July 2016 to November 2017. Neonates were included if they were born between 37 and 41 weeks gestational age (GA), were 24 and $72 \mathrm{~h}$ old, had the ability to suck, had an APGAR $\geq 8$ at 1 and 5 min after birth, needed a clinical blood sample taken for routine metabolic screening, and their mothers were BF. Exclusion criteria were congenital malformations, birth injuries (structural destruction or functional deterioration of the neonate's body due to a traumatic event at birth) ${ }^{14}$, a family history of genetic diseases with olfactory loss, and drug abuse or smoking by the mother.

\section{Randomization}

Randomization was performed using a randomization sequence generated by a free online available tool (randomizer.org). Patients were randomized 1:1 to the intervention or control group with no further stratification used during randomization.

\section{Intervention}

All neonates were positioned in their mother's arms, and the heel was exposed for access. Neonates were randomly assigned to one of two groups: Group 1 was given a vanilla-scented pacifier (Natus ${ }^{\circledR}$ GumDrop ${ }^{\circledR}$ ). Group 2 was breastfed (BF was determined to occur when a good latch was observed). Participants were provided the non-pharmacological method for $1 \mathrm{~min}$ before the heel stick and up to $5 \mathrm{~min}$ after the procedure. Testing for both groups was performed in the hospital's private room, where the mothers and their neonates were observed. The procedure was video recorded to have an accurate chronology of changes in the vital signs (heart rate [HR] through electrodes and oxygen saturation [OS] through a pulse oximeter on a limb), both of which are necessary for the Premature Infant Pain Profile (PIPP) scale. Heel puncture was done using a non-mechanical lancet by a trained and experienced nurse. The collection of variables and the video was done by a pediatric resident. A single trained neonatologist was responsible for providing a PIPP pain score to each newborn $30 \mathrm{~s}$ after the procedure.

\section{Pain measurement}

The PIPP is a scale used to assess acute pain in premature and full-term newborns. It includes behavioral (facial actions: brow bulge, eye squeeze, and nasolabial furrow), physiological (HR and OS), and two contextual (GA and behavioral state) indicators. Each indicator is evaluated on a four-point scale for a possible total score of 21. A total score of 6 or less assumes minimal, or no pain, scores between 7 and 12 indicate moderate pain, while scores $>12$ indicate severe pain. The scale has been rigorously evaluated and is a valid and reliable indicator of neonatal pain ${ }^{4,15}$.

\section{Sample size estimation}

The hypothesis to be tested was that infants treated with NNS using a vanilla-scented pacifier obtained a lower score on the PIPP (4) scale than those treated 


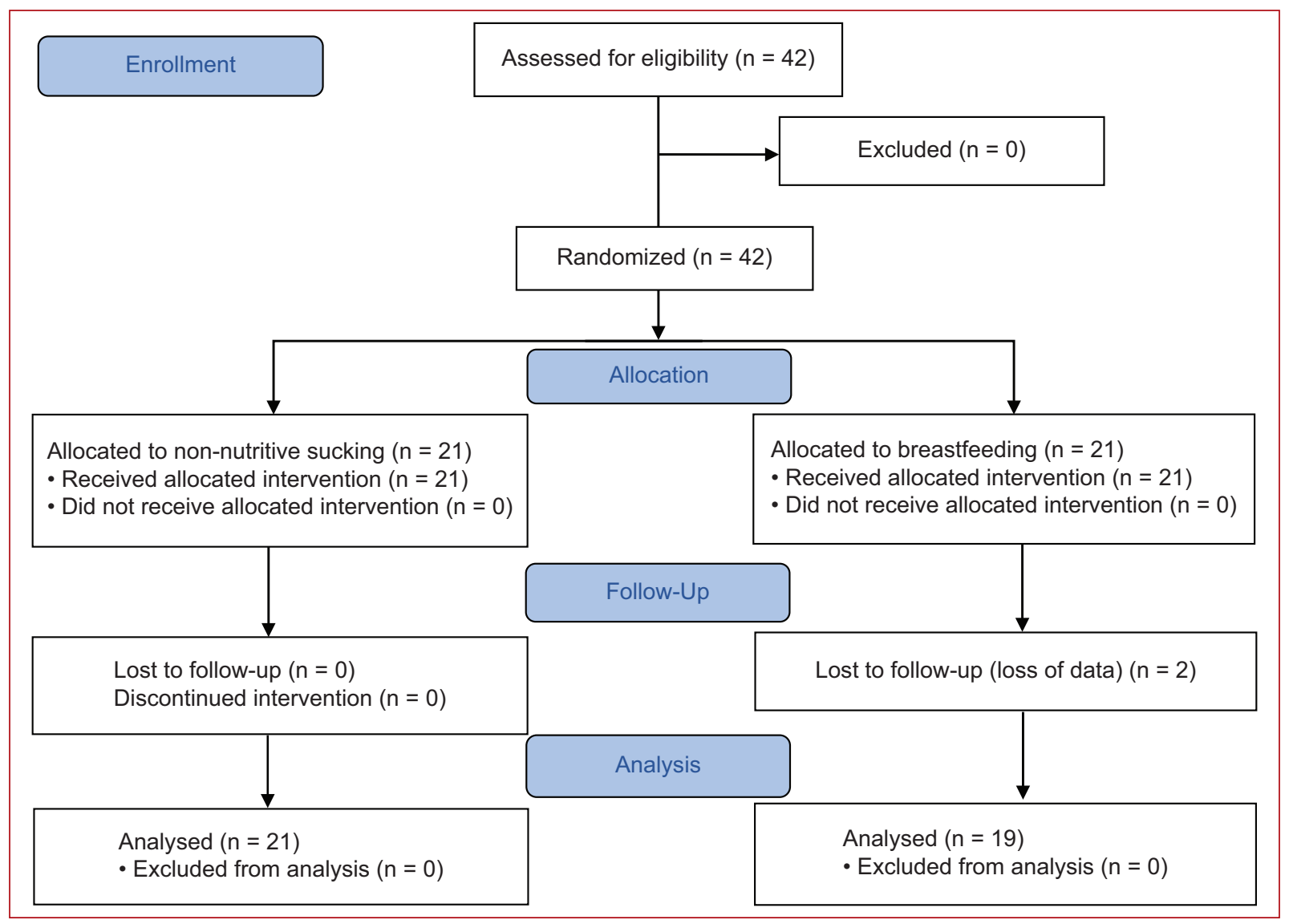

Figure 1. Enrollment flow diagram.

with BF (6). Using a formula for hypothesis testing and a difference of two means with a unilateral significance level of 0.5 and a power of $90 \%$, a sample of 21 participants per group was required.

\section{Adverse events}

Episodes of apnea, tachycardia, pallor, sweating, and shortness of breath were considered adverse events and data were collected by the pediatric resident during the intervention.

\section{Statistical analysis}

IBM SPSS Statistics for Windows, version 22 (IBM Corp., Armonk, NY, USA) was used to analyze data. We evaluated all variables if the weight distribution was assimilable to normal/non-normal distribution by calculating the kurtosis and asymmetry by applying the Kolmogorov-Smirnov test. Differences in the PIPP scores upon heel stick were compared using the Mann-Whitney $\mathrm{U}$ test. Differences in the baseline characteristics (sex, delivery type, and birth weight) and PIPP scale classification between the two groups were compared using the Chi-square. The student's t-test was used to analyze GA, length, head circumference, HR, and OS. We used a $p=0.05$ as the critical level of significance.

\section{Results}

\section{Baseline characteristics}

The mean maternal age in both groups was $26.15 \pm$ 6.17 years; marital status was 16 single $(40 \%), 1$ married $(2.5 \%)$, and $23(57.5 \%)$ by common law; education: 4 (10\%) elementary, 25 (62.5\%) secondary, 9 (22.5\%) preparatory, and $2(5 \%)$ college. A total of 40 full-term newborns 23 males (57.5\%) and 17 females (42.5\%) were recruited. The mean weight of the participants was $3440 \pm 449 \mathrm{~g}$. The enrollment flow diagram for this study was constructed based on the CONSORT guideline (Fig. 1). There were no significant differences between demographic variables, including sex, delivery type, GA, or birth weight/height/head circumference (Table 1). 
Table 1. Demographic characteristics of neonates

\begin{tabular}{|l|c|c|c|c|}
\hline & Total & NNS & Breastfeeding & p-value \\
\hline $\begin{array}{l}\text { Sex } \\
\text { Female } \\
\text { Male }\end{array}$ & $17(42.5)$ & $10(47.61)$ & $7(36.84)$ & $0.49^{1}$ \\
\hline $\begin{array}{l}\text { Delivery type } \\
\text { Vaginal } \\
\text { CS }\end{array}$ & $23(57.5)$ & $11(52.38)$ & $12(63.15)$ & $0.30^{1}$ \\
\hline $\begin{array}{l}\text { Birth weight } \\
\text { AGA }\end{array}$ & $16(40)$ & $10(47.61)$ & $6(31.57)$ & $0.48^{2}$ \\
\hline LGA & $24(60)$ & $11(52.38)$ & $13(68.42)$ & $3387 \pm 402$ \\
\hline SGA & $3440 \pm 449$ & $3488 \pm 492$ & $19(100)$ & $0.23^{1}$ \\
\hline Gestational age & $37(94.87)$ & $18(85.71)$ & $0(0)$ & $0.63^{2}$ \\
\hline Height & $1(.02)$ & $1(4.76)$ & $39.56 \pm 1.29$ & $0.49^{2}$ \\
\hline HC & $3(5.12)$ & $2(9.52)$ & $51 \pm 1.63$ & $0.65^{2}$ \\
\hline
\end{tabular}

Data are presented as $N(\%)$ or Mean \pm SD. AGA: adequate for gestational age, CS: cesarean section, HC: head circumference, LGA: large for gestational age, NNS: non-nutritive sucking, SGA: small for gestational age, SD: standard deviations.

${ }^{1}$ Chi-square test

${ }^{2}$ Student's t-test.

\section{PIPP score}

Following the heel stick, 6 subjects (15\%) experienced mild pain (PIPP score: 0-6), $13(32.5 \%)$ moderate pain (PIPP score: 7-12), and 21 (52.5\%) severe pain (PIPP score: 13-21). The mean score in both groups was $10.78 \pm 6.17$, and there was no significant difference in the classification or pain score between groups. The mean PIPP score in female infants was $11.76 \pm$ 2.68 and in male infants $10.04 \pm 3.82(p=0.12)$. The results are shown in table 2 .

\section{Physiological responses to pain}

\section{HR MEASUREMENTS}

In the NNS group, the HR increased and peaked 15 $S$ after the painful stimulus, while in the BF group, the $\mathrm{HR}$ decreased. Five minutes after the procedure, the $\mathrm{HR}$ in the NNS group decreased but increased and peaked in the BF group. The HR was compared before, during, and after the procedure between groups, and there was a significant difference $15 \mathrm{~s}$ after the heel stick (defined as during the procedure) (Table 3 ).

\section{OS MEASUREMENTS.}

OS decreased following the painful stimulus in both groups, but the mean OS only dropped below the normal range in the BF group. In both groups, OS was significantly lower than baseline at the time of the heel stick and $5 \mathrm{~min}$ following the procedure. No significant differences between groups were observed (Table 3).

\section{Facial coding scores}

There was no difference in behavioral indicators (brow bulge, eye squeeze, and nasolabial furrow) between groups (Table 3).

\section{Adverse events}

No adverse effects occurred during the study.

\section{Discussion}

Non-pharmacological interventions to reduce pain have been previously studied. Still, to the best of our knowledge, this is the first study that compares NNS through a vanilla-scented pacifier to BF to relieve pain in healthy term infants during a heel stick ${ }^{16}$. Our study showed that NNS and BF are easy methods to control acute pain in term infants during heel stick and are equally effective.

There are different scales to evaluate pain in neonates ${ }^{17-19}$. We decided to use the PIPP scale because it is reliable, valid, and its clinical usefulness is well established (procedural and post-operative pain)2. Since neonates can experience severe pain during heel sticks, we did not have a group without pain management for ethical reasons. We observed that 
Table 2. PIPP scores of groups

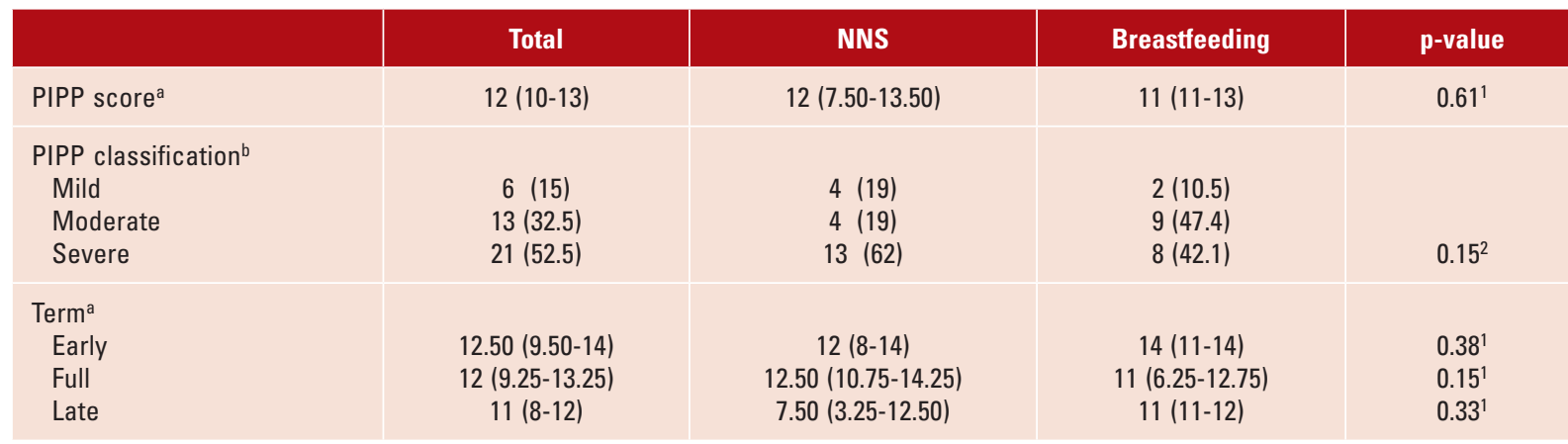

aData are shown as median (I0 range)

bData are shown as $\mathrm{N}$ (percentage)

'Mann-Whitney U test

${ }^{2}$ Chi-square test

NNS: non-nutritive sucking, PIPP: premature infant pain profile.

Table 3. Vital signs measures and facial coding scores of groups

\begin{tabular}{|c|c|c|c|}
\hline & NNS & Breastfeeding & p-value \\
\hline $\mathrm{HR}^{1}$ & $133.19 \pm 11.1$ & $131.74 \pm 12.26$ & $0.69^{4}$ \\
\hline $\mathrm{HR}^{2}$ & $143.10 \pm 11.89$ & $129.26 \pm 25.17$ & $0.03^{4}$ \\
\hline $\mathrm{HR}^{3}$ & $137.48 \pm 12.02$ & $135.32 \pm 14.37$ & $0.60^{4}$ \\
\hline $0 \mathrm{~S}^{1}$ & $96.48 \pm 2.16$ & $93.95 \pm 6.60$ & $0.10^{4}$ \\
\hline $0 S^{2}$ & $93.90 \pm 3.27$ & 90.327 .48 & $0.06^{4}$ \\
\hline $0 S^{3}$ & $95.90 \pm 3.19$ & $93.74 \pm 6.56$ & $0.18^{4}$ \\
\hline $\begin{array}{l}\text { Brow bulge } \\
\text { None } \\
\text { Minimum } \\
\text { Intermediate } \\
\text { Maximum }\end{array}$ & $\begin{array}{c}5(23.8 \%) \\
2(9.5 \%) \\
1(4.8 \%) \\
13(61.9 \%)\end{array}$ & $\begin{array}{c}1(5.3 \%) \\
2(10.5 \%) \\
4(21.1 \%) \\
12(63.2 \%)\end{array}$ & $0.22^{5}$ \\
\hline $\begin{array}{l}\text { Eye squeeze } \\
\text { None } \\
\text { Minimum } \\
\text { Intermediate } \\
\text { Maximum }\end{array}$ & $\begin{array}{c}4(19 \%) \\
2(9.5 \%) \\
0(0 \%) \\
15(71.4 \%)\end{array}$ & $\begin{array}{c}1(5.3 \%) \\
2(9.5 \%) \\
1(5.3 \%) \\
15(78.9 \%)\end{array}$ & $0.43^{5}$ \\
\hline $\begin{array}{l}\text { Nasolabial furrow } \\
\text { None } \\
\text { Minimum } \\
\text { Intermediate } \\
\text { Maximum }\end{array}$ & $\begin{array}{c}4(19 \%) \\
2(9.5 \%) \\
0(0 \%) \\
15(71.4 \%)\end{array}$ & $\begin{array}{c}1(5.3 \%) \\
2(10.5 \%) \\
3(15.8 \%) \\
13(68.4 \%)\end{array}$ & $0.18^{5}$ \\
\hline
\end{tabular}

Data are shown as media \pm SD and N (\%). HR: heart rate, OS: oxygen saturation, NNS: non-nutritive sucking

'Baseline ( $30 \mathrm{~s}$ before puncture)

${ }^{2} 15 \mathrm{~s}$ after the procedure

$30 \mathrm{~s}$ after the procedure

${ }^{4}$ Student's t-test

${ }^{5}$ Chi-square test

most infants treated with BF tended to be mostly classified as having mild and moderate pain instead of those treated with NNS, who were classified as having severe pain; nevertheless, no statistical significance was found. The use of a non-mechanical lancet could influence this because it is already known that they are more painful than automatic lancets. These results differ from other studies that found that neonates were mostly classified as having mild or moderate pain on the PIPP scale when different non-pharmacological methods are used ${ }^{20-21}$. Based on these results, we strongly recommend using a non-pharmacological method in the newborn nursery unit during heel sticks.

Results of our research support the study by Simonse et al. They found no difference in PIPP scores during a heel stick between human milk and sucrose in infants of 32-37 weeks gestation and concluded BF has an analgesic effect ${ }^{22}$.

We chose to use a vanilla-scented pacifier because it could have a synergistic analgesic effect with NNS. Jebreili et al. compared the calming effect of human milk odor and vanilla odor (10-g clean cotton ball dipped in 10 drops of vanilla solution) in preterm infants undergoing a heel stick procedure and found that human milk and vanilla odor had calming effects on premature infants during puncture because olfactory stimulation with familiar odors can have an analgesic effect on preterm and term neonates ${ }^{23}$.

Results of this study support the use of NNS as an option to treat pain when infants do not have access to $\mathrm{BF}$ such as when mothers cannot breastfeed or is unavailable. Vu-Ngoc et al. evaluated the analgesic effect of NNS by comparing a silicone pacifier versus routine care in healthy term neonates during a heel stick and concluded that NNS is a safe and effective method to relieve acute pain in term neonates ${ }^{24}$. 
Our results are consistent with the previous study of Pérez Ménde ${ }^{25}$, who demonstrated that BF's use was safe and effective in relieving pain in term neonates.

The BF group had less increase in HR compared to the NNS group. A statistical significance was found in the mean HR at the time of the lancet puncture in the heel. This supports studies that demonstrate that BF might reduce an increase in HR after procedures ${ }^{26-28}$. However, a Cochrane systematic review based on two articles where BF was compared to either swaddling or no intervention during immunization (MD $-4,95 \% \mathrm{Cl}$ -23-16; $p=0.03$ ) found no statistical significance difference in the incidence of increased HR, but the level of evidence was low according to the Grading of Recommendations, Assessment, Development, and Evaluation (GRADE) criteria and further studies are needed $^{29}$.

We compared the decrease in OS between groups and found no significant difference in the prevention of decreased OS between groups. Similarly, Okan et al. found no difference in mean OS changes between infants who received BF or skin-skin care for pain control ${ }^{30}$.

\section{Strengths and limitations of the study}

The study was originally conducted with 42 subjects and then they were randomly separated into two groups. One was an intervention group with NNS, and the other was a control group with BF. While our sample size was small, a power analysis suggests that it was large enough to test our hypothesis since we only lost $5 \%$ of participants. This study's main limitation was that we could not control the neonatologist in charge of giving the PIPP score to react naturally to which method we used. Another limitation to this study was the potential for bias by the neonatologist providing the PIPP score since subjective measurements such as facial expression can be scored differently by individuals. We recorded the neonates' full face to observe facial expressions to avoid bias. A strength of our study included the use of only one trained nurse conducting all the heel sticks.

\section{Conclusions}

Our study compared PIPP scores between using BF versus NNS through a vanilla-scented pacifier in term infants subjected to heel stick procedure and found no significant difference between groups in terms of pain relief. We found that BF tends not to increase the HR significantly; therefore, we found that BF tends not to increase the heart rate significantly; therefore, our recommendation is that BF could be a non-pharmacological method to treat pain in neonates with mild or moderate pain.

\section{Conflicts of interest}

None declared.

\section{Acknowledgments}

None declared.

\section{Ethical disclosures}

Protection of human and animal subjects. The authors declare that the procedures followed were in accordance with the regulations of the relevant clinical research ethics committee and with those of the Code of Ethics of the World Medical Association (Declaration of Helsinki).

Confidentiality of data. The authors declare that they have followed the protocols of their work center on the publication of patient data.

Right to privacy and informed consent. The authors have obtained the written informed consent of the patients or subjects mentioned in the article. The corresponding author is in possession of this document.

\section{References}

1. Raja SN, Carr DB, Cohen M, Finnerup NB, Flor H, Gibson S, et al. The revised international association for the study of pain definition of pain: concepts, challenges, and compromises. Pain. 2020;161:1976-82.

2. Krishnan L. Pain relief in neonates. J Neonatal Surg. 2013;2:19.

3. Bhalla T, Shepherd E, Tobias JD. Neonatal pain management. Saudi J Anaesth. 2014;8 Suppl 1:S89-97.

4. Witt N, Coynor S, Edwards C, Bradshaw H. A guide to pain assessment and management in the neonate. Curr Emerg Hosp Med Rep. 2016:4:1-10.

5. Hall RW, Anand KJ. Pain management in newborns. Clin Perinatol. 2014;41:895-924.

6. Benoit B, Martin-Misener R, Latimer M, Campbell-Yeo M. Breast-feeding analgesia in infants: an update on the current state of evidence. J Perinat Neonatal Nurs. 2017;31:145-59.

7. Shah PS, Aliwalas LI, Shah V. Breastfeeding or breast milk for procedural pain in neonates. Cochrane Database Syst Rev. 2006;3:CD004950.

8. Harrison D, Larocque C, Bueno M, Stokes Y, Turner L, Hutton B, et al. Sweet solutions to reduce procedural pain in neonates: a meta-analysis. Pediatrics. 2017;139:e20160955.

9. Johnston C, Campbell-Yeo M, Disher T, Benoit B, Fernandes A Streiner D, et al. Skin-to-skin care for procedural pain in neonates. Cochrane Database Syst Rev. 2017;2:CD008435.

10. Mangat A, Oei J, Chen K, Quah-Smith I, Schmölzer G. A review of non-pharmacological treatments for pain management in newborn infants. Children (Basel). 2018;5:130.

11. Merskey H, Albe Fessard D, Bonica JJ, Carmon A, Dubner R, Kerr FWL, et al. Prevention and Management of Procedural Pain in the Neonate: An Update. Pediatrics. 2016;137(2):e20154271-e20154271. doi:10.1542/ peds.2015-4271.

12. American Academy of Pediatrics, Committee on Psychosocial Aspects of Child and Family Health, Task Force on Pain in Infants, Children, and Adolescents. The assessment and management of acute pain in infants, children, and adolescents. Pediatrics. 2001;108:793-7. 
13. Thakkar P, Arora K, Goyal K, Das RR, Javadekar B, Aiyer S, et al. To evaluate and compare the efficacy of combined sucrose and non-nutritive sucking for analgesia in newborns undergoing minor painful procedure: a randomized controlled trial. J Perinatol. 2016;36:67-70.

14. Akangire G, Carter B. Birth injuries in neonates. Pediatr Rev. 2016;37:451-62.

15. RNAO. Clinical best practice guidelines. In: Assessment and Management of Pain. $3^{\text {rd }}$ ed. Canada: RNAO; 2013. p. 43. Available from: http:// www.rnao.ca/sites/rnao-ca/files/assessandmanagementofpain2014.pdf.

16. Riddell RR, Racine NM, Gennis HG, Turcotte K, Uman LS, Horton RE et al. Non-pharmacological management of infant and young child procedural pain. Cochrane Database Syst Rev. 2015;2015:CD006275.

17. Krechel SW, Bildner J. CRIES: a new neonatal postoperative pain measurement score. Initial testing of validity and reliability. Paediatr Anaesth. 1995;5:53-61

18. Voepel-Lewis T, Merkel S, Tait AR, Trzcinka A, Malviya S. The reliability and validity of the face, legs, activity, cry, consolability observational too as a measure of pain in children with cognitive impairment. Anesth Analg. 2002;95:1224-9.

19. Lawrence J, Alcock D, McGrath P, Kay J, MacMurray SB, Dulberg C. The development of a tool to assess neonatal pain. Neonatal Netw. 1993;12:59-66.

20. Elserafy FA, Alsaedi SA, Louwrens J, Bin SB, Mersal AY. Oral sucrose and a pacifier for pain relief during simple procedures in preterm infants: a randomized controlled trial. Ann Saudi Med. 2009;29:184-8

21. Committee on Fetus and Newborn and Section on Anesthesiology and Pain Medicine. Prevention and management of procedural pain in the neonate: an update. Pediatrics. 2016;137:e20154271.
22. Simonse $\mathrm{E}$, Mulder $\mathrm{PG}$, van Beek RH. Analgesic effect of breast milk versus sucrose for analgesia during heel lance in late preterm infants. Pediatrics. 2012;129:657-63.

23. Jebreili M, Neshat $H$, Seyyedrasouli A, Ghojazade M, Hosseini MB, Hamishehkar H. Comparison of breastmilk odor and vanilla odor on mitigating premature infants' response to pain during and after venipuncture. Breastfeed Med. 2015;10:362-5.

24. Vu-Ngoc H, Uyen NC, Thinh OP, Don LD, Vo Tan Danh N, Truc NT, et al. Analgesic effect of non-nutritive sucking in term neonates: a randomized controlled trial. Pediatr Neonatol. 2020;61:106-13.

25. Pérez-Méndez BB, Ochoa-Correa EC, Treviño-Garza C, Cortés-Flores DC, Bocanegra-Cedillo JI, Flores-Rodríguez A, et al. Analgesic effects of maternal breast milk and sucrose in early, full, and late-term neonates. Rev Med Univ. 2019;21:169-74.

26. Razek AA, Az El-Dein N. Effect of breast-feeding on pain relief during infant immunization injections. Int J Nurs Pract. 2009;15:99-104.

27. Efe $E$, Özer ZC. The use of breastfeeding for pain relief during neonatal mmunization injections. Appl Nurs Res. 2007;20:10-6.

28. Erkul M, Efe E. Efficacy of breastfeeding on babies' pain during vaccinations. Breastfeed Med. 2017;12:110-5

29. Harrison D, Reszel J, Bueno M, Sampson M, Shah VS, Taddio A, et al. Breastfeeding for procedural pain in infants beyond the neonatal period. Cochrane Database Syst Rev. 2016;10:CD011248.

30. Okan F, Ozdil A, Bulbul A, Yapici Z, Nuhoglu A. Analgesic effects of skin-to-skin contact and breastfeeding in procedural pain in healthy term neonates. Ann Trop Paediatr. 2010;30:119-28. 